\title{
New strategic insights into managing fungal biofilms
}

\section{Elisa Borghi ${ }^{1 *}$, Giulia Morace ${ }^{1}$, Francesca Borgo ${ }^{1}$, Ranjith Rajendran ${ }^{2}$, Leighann Sherry ${ }^{2}$, Christopher Nile ${ }^{2}$ and Gordon Ramage ${ }^{2}$}

${ }^{1}$ Laboratory of Microbiology, Department of Health Sciences, Università degli Studi di Milano, Milan, Italy, ${ }^{2}$ Infection and Immunity Research Group, Glasgow Dental School, School of Medicine, University of Glasgow, Glasgow, UK

Fungal infections have dramatically increased in the last decades in parallel with an increase of populations with impaired immunity, resulting from medical conditions such as cancer, transplantation, or other chronic diseases. Such opportunistic infections result from a complex relationship between fungi and host, and can range from self-limiting to chronic or life-threatening infections. Modern medicine, characterized by a wide use of biomedical devices, offers new niches for fungi to colonize and form biofilm communities. The capability of fungi to form biofilms is well documented and associated with increased drug tolerance and resistance. In addition, biofilm formation facilitates persistence in the host promoting a persistent inflammatory condition. With a limited availability of antifungals within our arsenal, new therapeutic approaches able to address both host and pathogenic factors that promote fungal disease progression, i.e., chronic inflammation and biofilm formation, could represent an advantage in the clinical setting. In this paper we discuss the antifungal properties of myriocin, fulvic acid, and acetylcholine in light of their already known anti-inflammatory activity and as candidate dual action therapeutics to treat opportunistic fungal infections.

Keywords: biofilm-related infections, antifungal resistance, myriocin, fulvic acid, acetylcholine

\section{Introduction}

The population of subjects at risk of developing fungal infections is steadily increasing due to rising life expectancy and the continuous medical progress in the treatment of serious diseases such as cancer, transplantation or impairment of immune system (Brown et al., 2012).

Even though advanced medical treatments allow these patients to live longer, the exposure to surgery and medical devices composed of polymeric materials results in evolved ecological niches for biofilm-producing microorganisms and increases the risk for infectious diseases, including those caused by opportunistic fungi (Ramage et al., 2006). Candida albicans amongst yeasts and Aspergillus fumigatus amongst molds are still the most common pathogens in the clinical setting (Morace and Borghi, 2010; Kriengkauykiat et al., 2011; Guinea, 2014), and continue to carry a high mortality despite the antifungal treatment.

Antifungal resistance is emerging in Candida and Aspergillus species (Arendrup, 2014), and together with intrinsic or acquired mechanisms, the drug tolerance related to biofilm formation is emerging as having a crucial role in the failure of treatments (Ramage et al., 2014). Fungal cells within the biofilms display resistance to azoles and polyenes, at least at therapeutic doses (Taff et al., 2013). Echinocandins seem to achieve better results against Candida biofilms, but not against $A$. fumigatus (Pierce et al., 2013). Thus, the development of new compounds able to overcome the drug-resistance of biofilms is undoubtedly a current and, even more, a future medical need for the treatment of such infections. 
Recently, some compounds with known anti-inflammatory properties have been investigated for their antifungal activity. This is of particular relevance in the context of fungal infections. The interplay between fungus and host, i.e., immune system and inflammatory milieu, is crucial in determining the tolerance or the disease status (Romani, 2011). Although inflammation is required to control of fungal infections, its resolution is necessary to avoid collateral damage to tissues and to restore a homeostatic environment (Romani, 2011). Drugs displaying dual activity, antifungal and anti-inflammatory, could thus represent novel approaches to treat biofilm-related infections. In this work we discuss the anti-biofilm properties of myriocin, fulvic acid, and acetylcholine, three compounds recently investigated for their antifungal activity in the context of fungal biofilms.

\section{Myriocin}

Sphingolipids (SPLs) are a class of molecules with structural and signaling activities conserved from fungi to humans. Many studies have demonstrated that SPL mediators are involved in infection-related mechanisms (Mor et al., 2015). Both microbial and mammalian dysregulation of SPLs play a role in the delicate relationship between pathogen and host during the infection process, having an impact on signaling pathways that eventually lead to commensalism or host damage (Heung et al., 2006).

Fungal SPLs have been implicated in several cellular processes such as endocytosis, apoptosis, heat stress response, and fungal pathogenesis (Lattif et al., 2011). In fact, SPLs are part, together with ergosterol, of plasma membrane domains named lipid rafts that are crucial for cell signaling and membrane trafficking, and mediate protein-protein interactions (Farnoud et al., 2015).

Changes in the SPLs content could thus strongly impact the local membrane structure and alter specific protein localization such as the GPI-anchored proteins (Singh and Del Poeta, 2011). These have been extensively studied in C. albicans and are crucial for adhesion to substrates in the early phases of biofilm formation (Cabral et al., 2014). Differences in SPLs content have been observed in planktonic and sessile cells of C. albicans, suggesting a role for the lipid moiety in biofilm formation and maturation (Lattif et al., 2011). Lipid rafts have been found to localize at the hyphal tip, and drugs affecting SPLs biosynthesis, such as myriocin, lead to defects in hypha formation (Martin and Konopka, 2004).

Myriocin targets the first step of SPLs de novo biosynthesis, by inhibiting the enzyme serine palmitoyl transferase (SPT) that catalyzes the condensation of a fatty acyl CoA with serine, a common step to both fungal and mammalian SPLs biosynthesis.

Many cell-stress responses cause ceramide, the central molecule of SPL metabolism, to accumulate and trigger the activation of inflammatory processes (Hannun and Obeid, 2008). High levels of ceramide are characteristic of several inflammatory diseases. Animal models showed that myriocin treatment is able to reduce inflammation by down-regulating ceramide and its related proinflammatory cascade (Jiang et al., 2011; Lee et al., 2012; Caretti et al., 2014).

Besides this action and similarly to other SPLs metabolism inhibitors (Groll et al., 1998; Mormeneo et al., 2008), myriocin has a direct antifungal activity (Martin and Konopka, 2004; Lattif et al., 2011; de Melo et al., 2013; Sharma et al., 2014). Recently, Lattif et al. (2011) assessed a potential antibiofilm activity for the drug. The authors grew C. albicans biofilms in the presence and absence of various myriocin concentrations and observed a progressive reduction in biofilm biomass and metabolic activity. In addition, lipid raft formation was strongly reduced as well as the C. albicans filamentation (Lattif et al., 2011).

Myriocin has been found to be also active against $A$. fumigatus (Cirasola et al., 2014). Administration of myriocin to conidia resulted in a dose-dependent inhibition of germination, whereas the treatment of $24 \mathrm{~h}$ pre-formed biofilms strongly reduced the biofilm biomass, as determined by crystal violet assay, and the metabolic activity. In particular, myriocin led to the presence of aberrant hyphal structures in A. fumigatus, with increased branching and reduction in apical hyphal growth. Hyphal polarization and branching in A. fumigatus, as well as filamentation in C. albicans, have been shown to be crucial for virulence and biofilm formation, resulting in more stable biofilms (Brand, 2012; Riquelme, 2013). The inhibition of SPL metabolism disrupts the actin organization at the tip, impacting on normal hyphal growth and differentiation (Cheng et al., 2001). Moreover, a deprived quantity of SPLs results in a decrease of SPLs in lipid rafts with a subsequent reduction of plasma membraneanchored proteins that participate in the maintenance of polarized growth (Momany, 2002). Although the compound is also active against planktonic fungal cells, all the major SPLs classes seem to be over-represented in the biofilm-organized cells (Lattif et al., 2011), suggesting a key role for SPLs in modulating biofilm formation.

To improve the delivery of myriocin, a highly lipophilic compound, Strettoi et al. (2010) explored the use of solid lipid nanocarriers in a mice model of retinitis pigmentosa. Similarly, other authors observed a decrease in the effective drug concentration compared with pure compound when using nanocarrier delivery in a cystic fibrosis mouse model (Caretti et al., 2014). By treating mice with intratrachea myriocin-loaded nanocarriers, Caretti et al. (2014) were able to achieve a reduction of lung infection and inflammation after Pseudomonas aeruginosa infection.

Due to the poor penetration of biofilm matrix by drugs, the same nanocarriers were investigated on fungal biofilms. Nanocarriers improved myriocin delivery into $A$. fumigatus biofilms, allowing its distribution within few hours even in bottom layers (Cirasola et al., 2014).

Due to its dual action, anti-inflammatory and antifungal, myriocin might represent a useful treatment for patients suffering from chronic diseases that increase the risk of fungal infections. However, deeper investigations into its administration need to be performed. Recently de Melo et al. (2013) observed that prophylaxis treatment with myriocin, in an invertebrate model of systemic candidiasis, reduces the insect survival (de Melo et al., 2013). The optimal scenario for the myriocin use could be late phases of fungal infection as well as pathological situations characterized by ceramide mediated hyper-inflammation. On the other hand, the development of myriocin derivatives as well as other compounds targeting downstream steps in the fungal 
SPL synthesis could increase the specificity of these compounds against fungal enzymes avoiding host side effects.

\section{Fulvic Acid}

Humic substances are commonly found in decaying organic matter including plants, animal residues, sewage and soil (Snyman et al., 2002). Although fulvic acids account for $\sim 90 \%$ of all humic substances and their biological significance recognized for many years (van Rensburg et al., 2000), there is still minimal scientific understanding on which to support the claims of its biological properties. Oxifulvic acid, a derivate of fulvic acid, has been shown to elicit antibacterial and antifungal properties (van Rensburg et al., 2000). However, these formulations contain numerous toxic elements that make their use clinically impossible. Recently, there has been the development of a pure form of fulvic acid, carbohydrate derived fulvic acid (CHD-FA), that has been shown to be safe to use clinically and absent from environmental contaminants known to be harmful to the host (Gandy et al., 2011).

An initial randomized double blind controlled trial indicated that fulvic acid was well-tolerated in patients with eczema, where side effects were minimal and severity and erythema were significantly reduced compared with the placebo control (Gandy et al., 2011). A subsequent phase 1 clinical study carried out to determine the safety profile of CHD-FA, showed that this agent was able to elicit anti-inflammatory properties in addition to being non-toxic when used as an oral formulation (Gandy et al., 2012). This anti-inflammatory activity was also shown in a rat wound model, where the use of a topical cream enhanced wound healing and was non-toxic during both acute and chronic treatments (Sabi et al., 2012). However, so far the mechanism by which CHD-FA elicits the observed immunomodulatory effects is unknown.

Although the anti-inflammatory properties of CHD-FA have been studied, there are very few reports of the antimicrobial properties of this agent. Recent studies have shown CHD-FA to be fungicidal against C. albicans planktonic and sessile cells at similar concentrations, indicating good biofilm activity unlike azole antifungals (Sherry et al., 2012). Time-kill analysis of CHD-FA was performed in comparison to the other classes of antifungals, and whilst caspofungin achieved the greatest kill, CHD-FA elicited its maximum activity quicker than any of the other agents, which is of particular benefit in treating systemic infections such as candidemia, where delayed antifungal therapy coincides with mortality rates (Morrell et al., 2005). The rapid killing action was further analyzed by visualizing the uptake of propidium iodide by the cells, only feasible when the cell membrane has been compromised. Membrane damage was recorded as early as 10 min following CHD-FA exposure, which also correlates with the release of intracellular ATP from the cell (Sherry et al., 2012). To further test the hypothesis of a membrane active compound, the activity against the $C$. albicans cell membrane was investigated using a chitin synthase inhibitor. Chitin is a simple polysaccharide found in the cell walls of fungi that provides cell structure and rigidity (Lenardon et al., 2010). It was argued that if the cell membrane was the target of CHD-FA, then by weakening the cell by inhibiting its chitin production would increase the exposure of the cell membrane to the agent and would increase CHD-FA sensitivity (Sherry et al., 2012). Here it was demonstrated that $C$. albicans cells were hyper-susceptible to CHD-FA in the presence of a chitin synthase inhibitor, a finding that was also observed in voriconazole treated biofilms (Kaneko et al., 2010). Collectively, these data suggest that CHD-FA acts through disruption to the cell membrane. It is therefore feasible to suggest that this agent may have broad-spectrum antimicrobial activity against a variety of fungi and bacteria. Indeed, this was the case when CHD-FA was shown to possess antibacterial activity toward a range of oral bacterial biofilms, including an in vitro four-species periodontal biofilm model (Sherry et al., 2013).

Additionally, fulvic acid was shown to be minimally affected by characterized biofilm resistance mechanisms, including the extracellular matrix (ECM) and efflux pumps. For example, it is known that glucans within the cellular matrix hinder the penetration of azoles through biofilms, with the depletion of FKS1, encoding a $\beta-1,3$ glucan synthase, increasing the susceptibility of fluconazole within these communities (Nett et al., 2010a,b). Overexpression of $F K S 1$, as well as a deletion mutant, was used to determine the impact of CHD-FA activity. Here it was shown that this agent's sensitivity was not compromised by the elevated expression of $F K S 1$, which is in contrast to azoles, polyenes and echinocandins, where the matrix sequesters these agents and their activity is significantly reduced against C. albicans biofilms (Nett et al., 2010a).

Efflux pumps have been widely shown to play a role in azole resistance within Candida biofilms, particularly during early biofilm development both in vitro and in vivo (Ramage et al., 2002; Mukherjee et al., 2003; Nett et al., 2009). Although CHD-FA was shown to induce efflux pump activity in C. albicans biofilms, there was no change in the minimum inhibitory concentration (MIC) when an efflux pump inhibitor was used, demonstrating that CHD-FA activity is not compromised by these pumps unlike other antifungals (Sherry et al., 2012).

Overall, whilst our knowledge base for CHD-FA is relatively limited, it does appear to have appropriate biological properties of a broad-spectrum antimicrobial agent and not compromised by know biofilm resistance mechanisms, which has yet undefined immunomodulatory capacity. Further in vitro and in vivo studies are required to determine its safety profile.

\section{Acetylcholine}

Bi-directional neurochemical interactions occur between the host and colonizing microorganisms (Lyte, 2013, 2014a,b; Sandrini et al., 2015). Many microorganisms share neuro-endocrine mediator synthesis pathways and recognition receptors with their human hosts (Lyte, 2013). Therefore, it is hypothesized that there is constant communication between a vertebrate host and its microbiota, and a bi-directional influence on behavior (Freestone, 2013). However, many of the inter-kingdom signaling molecules and receptors, particularly from the fungal perspective, remain to be characterized in detail. Furthermore, the biological consequences of neuro-endocrine signaling in fungi, with respect to growth and pathogenicity, are only just beginning to be determined. 
Acetylcholine (ACh) is widely distributed in both prokaryotic and eukaryotic cells. In mammalian systems, ACh has two major roles: (1) neuronal ACh acts as a neurotransmitter to mediate rapid communication between neurons and effector cells and (2) non-neuronal ACh acts as a local signaling molecule involved in the regulation of cellular phenotype, modification of ciliary activity, and modification of cell-cell contact (Wessler and Kirkpatrick, 2008). In recent years ACh has received greater attention due to the discovery of the "cholinergic antiinflammatory pathway" that has been demonstrated to regulate immune responses (Borovikova et al., 2000). In this pathway, $\mathrm{ACh}$ released from efferent vagus nerve terminals interacts with the alpha 7 nicotinic receptor $(\alpha 7 \mathrm{nAChR})$ on proximal immune cells resulting in down regulated localized immune responses. In addition, the efferent vagus nerve interacts with the splenic nerve to activate a unique ACh-producing memory phenotype T-cell population, which can propagate ACh mediated immune-regulation throughout the body (Rosas-Ballina et al., 2011). Furthermore, as ACh is also produced by cells out with neural networks, non-neuronal ACh can also play a vital role in localized immune-regulation through its cytotransmitter capabilities (de Jonge et al., 2005; Macpherson et al., 2014). In addition, evidence also suggests that ACh signaling through other cholinergic receptor subtypes, such as the muscarinic receptors, can also modulate inflammatory responses in mammalian systems (Verbout and Jacoby, 2012).

Interestingly, in a recent study, $\mathrm{ACh}$ was found to play multiple roles in the pathogenesis of fungal infections in a primitive Galleria mellonella infection model. Specifically, ACh was found to: (i) inhibit C. albicans yeast-to-hyphae transition and biofilm formation; (ii) promote a rapid and effective cellular immune response to $C$. albicans infection; and (iii) regulate antifungal defenses to limit sepsis induced damage of host tissues (Rajendran et al., 2015). The fact that ACh can directly act on $C$. albicans to inhibit yeast-to-hyphae transition suggests that this organism possesses a functional ACh receptor. However, the ACh receptor(s) and the downstream signaling pathway(s) that are involved in inhibiting C. albicans yeast-to-hyphae transition have yet to be characterized in detail.

Sequencing of the $C$. albicans genome has suggested this organism possesses putative cholinergic receptor genes (Inglis et al., 2012). Furthermore, pharmacological evidence suggests that C. albicans may possess a receptor that is homologous to human muscarinic (M) receptors. Midkiff et al. (2011) demonstrated that the dopamine receptor antagonist clozapine could inhibit $C$. albicans budding-to-hyphal transition by inhibiting a component of the Efg1 pathway, upstream of the Gpa2 G-alpha subunit, which the authors hypothesized to be the Gpr1 G-protein-coupled receptor (GPCR). However, clozapine has a broad range complex pharmacological profile. Indeed, it is now known that clozapine is a weak dopamine D2 receptor inverse agonist/antagonist and has mixed agonist-antagonist properties on human muscarinic receptors, with strong evidence that it can act as a potent agonist of the M1 and M4 receptors in mammalian systems (Zorn et al., 1994; Olianas et al., 1997, 1999; Miller, 2009; Wiebelhaus et al., 2012). Therefore, it is interesting to speculate that the observed effects on C. albicans budded-to-hyphal transition in the study of Midkiff et al. (2011) may be in fact due to clozapine acting upon a putative C. albicans cholinergic receptor homologous to human muscarinic receptors. However, further research aimed at characterizing the cholinergic receptor mediated signaling pathways of C. albicans is required to confirm this hypothesis.

There is also substantial evidence to suggest that fungi can synthesize and release ACh (Horiuchi et al., 2003; Kawashima and Fujii, 2008). Indeed, sequencing of the C. albicans genome revealed this organism to possess putative genes for the enzymes responsible for ACh synthesis; choline acetyltransferase (ChAT) and carnitine acetyltransferase (CrAT; Inglis et al., 2012). However, the ACh synthesis machinery of $C$. albicans remains to be characterized. Furthermore, the biological functions of fungal derived ACh remain to be elucidated.

The fact that both $C$. albicans and its human host both synthesize $\mathrm{ACh}$ and possess cholinergic receptors lead to speculate that there is cholinergic mediated bi-directional communication between the two species in vivo. The role of this cholinergic bidirectional communication in the maintenance of health and/or the pathogenesis of C. albicans infections are at present unknown. The evidence to date suggests the host may utilize ACh to protect against candidiasis (Rajendran et al., 2015). Although, the fact that ACh can modulate host immunity (Tracey, 2010) and also mucosal integrity through the regulation of epithelial cell phenotype and cell-cell contact (Wessler and Kirkpatrick, 2008), may also suggest that $C$. albicans derived ACh may be a potential virulence factor. Either way, further research into the role of bidirectional cholinergic signaling mechanisms between C. albicans and the colonized host is required.

The preliminary data to date imply that cholinergic mechanisms may be rational novel therapeutic targets to prevent or treat candidiasis (Rajendran et al., 2015). Indeed, there are a number of pharmacological agonists and antagonists already marketed for the treatment of neurodegenerative disorders, cancers and chronic inflammatory diseases that target cholinergic receptors (Pohanka, 2012; Zoheir et al., 2012; Sales, 2013; Matera and Tata, 2014; Russo et al., 2014). Many of these molecules have already undergone extensive safety and efficacy testing in human trials. Therefore, one or more of these molecules may be worthy of investigation for the prevention or treatment of candidiasis and may offer novel therapeutic approaches beyond conventional antifungals.

\section{Concluding Remarks}

The opportunistic nature of fungal infections highlights the crucial role of the host immune system in regulating host-fungus interactions.

Humans suffer from a range of fungal biofilm diseases that cause high levels of morbidity and mortality. Conventional antifungal drugs have been demonstrated to ineffective against fungal biofilms, and alternative strategies are needed to overcome their intrinsic resistance.

Therefore molecules targeting both fungal biofilm formation and the host inflammatory response could represent a new therapeutic approach to treat fungal biofilm-related infections with broader implications for healthcare applications. 


\section{References}

Arendrup, M. C. (2014). Update on antifungal resistance in Aspergillus and Candida. Clin. Microbiol. Infect. 20(Suppl. 6), 42-48. doi: 10.1111/1469-0691.12513

Borovikova, L. V., Ivanova, S., Zhang, M., Yang, H., Botchkina, G. I., Watkins, L. R., et al. (2000). Vagus nerve stimulation attenuates the systemic inflammatory response to endotoxin. Nature 405, 458-462. doi: 10.1038/35013070

Brand, A. (2012). Hyphal growth in human fungal pathogens and its role in virulence. Int. J. Microbiol. 2012, 517529. doi: 10.1155/2012/517529

Brown, G. D., Denning, D. W., Gow, N. A., Levitz, S. M., Netea, M. G., and White, T. C. (2012). Hidden killers: human fungal infections. Sci. Transl. Med. 4, 165rv13. doi: $10.1126 /$ scitranslmed.3004404

Cabral, V., Znaidi, S., Walker, L. A., Martin-Yken, H., Dague, E., Legrand, M., et al. (2014). Targeted changes of the cell wall proteome influence Candida albicans ability to form single- and multi-strain biofilms. PLoS Pathog. 10:e1004542. doi: 10.1371/journal.ppat.1004542

Caretti, A., Bragonzi, A., Facchini, M., De Fino, I., Riva, C., Gasco, P., et al. (2014). Anti-inflammatory action of lipid nanocarrier-delivered myriocin: therapeutic potential in cystic fibrosis. Biochim. Biophys. Acta 1840, 586-594. doi: 10.1016/j.bbagen.2013.10.018

Cheng, J., Park, T. S., Fischl, A. S., and Ye, X. S. (2001). Cell cycle progression and cell polarity require sphingolipid biosynthesis in Aspergillus nidulans. Mol. Cell. Biol. 21, 6198-6209. doi: 10.1128/MCB.21.18.6198-6209.2001

Cirasola, D., Perdoni, F., Biggiogera, M., Signorelli, P., Morace, G., and Borghi, E. (2014). Antifungal activity of myriocin, a sphingolipid metabolism inhibitor, on fungal biofilms: a preliminary study. Abstract From the 24th European Conference on Clinical Microbiology and Infectious Diseases; 2014 May 10-13, Barcelona.

de Jonge, W. J., van der Zanden, E. P., The, F. O., Bijlsma, M. F., van Westerloo, D. J., Bennink, R. J., et al. (2005). Stimulation of the vagus nerve attenuates macrophage activation by activating the Jak2-STAT3 signaling pathway. Nat. Immunol. 6, 844-851. doi: 10.1038/ni1229

de Melo, N. R., Abdrahman, A., Greig, C., Mukherjee, K., Thornton, C., Ratcliffe, N. A., et al. (2013). Myriocin significantly increases the mortality of anonmammalian model host during Candida pathogenesis. PLoS ONE 8:e78905. doi: 10.1371/journal.pone.0078905

Farnoud, A. M., Toledo, A. M., Konopka, J. B., Del Poeta, M., and London, E. (2015). Raft-like membrane domains in pathogenic microorganisms. Curr. Top. Membr. 75, 233-268. doi: 10.1016/bs.ctm.2015.03.005

Freestone, P. (2013). Communication between bacteria and their hosts. Scientifica (Cairo) 2013, 361073. doi: 10.1155/2013/361073

Gandy, J. J., Meeding, J. P., Snyman, J. R., and Van Rensburg, C. E. (2012). Phase 1 clinical study of the acute and subacute safety and proof-of-concept efficacy of carbohydrate-derived fulvic acid. Clin. Pharmacol. 4, 7-11. doi: 10.2147/CPAA.S25784

Gandy, J. J., Snyman, J. R., and Van Rensburg, C. E. (2011). Randomized, parallelgroup, double-blind, controlled study to evaluate the efficacy and safety of carbohydrate-derived fulvic acid in topical treatment of eczema. Clin. Cosmet. Investig. Dermatol. 4, 145-148. doi: 10.2147/CCID.S23110

Groll, A. H., De Lucca, A. J., and Walsh, T. J. (1998). Emerging targets for the development of novel antifungal therapeutics. Trends Microbiol. 6, 117-124. doi: 10.1016/S0966-842X(97)01206-7

Guinea, J. (2014). Global trends in the distribution of Candida species causing candidemia. Clin. Microbiol. Infect 20(Suppl. 6), 5-10. doi: 10.1111/14690691.12539

Hannun, Y. A., and Obeid, L. M. (2008). Principles of bioactive lipid signalling: lessons from sphingolipids. Nat. Rev. Mol. Cell Biol. 9, 139-150. doi: $10.1038 / \mathrm{nrm} 2329$

Heung, L. J., Luberto, C., and Del Poeta, M. (2006). Role of sphingolipids in microbial pathogenesis. Infect. Immun. 74, 28-39. doi: 10.1128/IAI.74.1.2839.2006

Horiuchi, Y., Kimura, R., Kato, N., Fujii, T., Seki, M., Endo, T., et al. (2003). Evolutional study on acetylcholine expression. Life Sci. 72, 1745-1756. doi: 10.1016/S0024-3205(02)02478-5

Inglis, D. O., Arnaud, M. B., Binkley, J., Shah, P., Skrzypek, M. S., Wymore, F., et al. (2012). The Candida genome database incorporates multiple Candida species: multispecies search and analysis tools with curated gene and protein information for Candida albicans and Candida glabrata. Nucleic Acids Res. 40, D667-D674. doi: $10.1093 / \mathrm{nar} / \mathrm{gkr} 945$
Jiang, X. C., Goldberg, I. J., and Park, T. S. (2011). Sphingolipids and cardiovascular diseases: lipoprotein metabolism, atherosclerosis and cardiomyopathy. $A d v$. Exp. Med. Biol. 721, 19-39. doi: 10.1007/978-1-4614-0650-1_2

Kaneko, Y., Ohno, H., Fukazawa, H., Murakami, Y., Imamura, Y., Kohno, S. et al. (2010). Anti-Candida-biofilm activity of micafungin is attenuated by voriconazole but restored by pharmacological inhibition of Hsp90-related stress responses. Med. Mycol. 48, 606-612. doi: 10.3109/13693780903426721

Kawashima, K., and Fujii, T. (2008). Basic and clinical aspects of non-neuronal acetylcholine: overview of non-neuronal cholinergic systems and their biological significance. J. Pharmacol. Sci. 106, 167-173. doi: 10.1254/jphs.FM0070073

Kriengkauykiat, J., Ito, J. I., and Dadwal, S. S. (2011). Epidemiology and treatment approaches in management of invasive fungal infections. Clin. Epidemiol. 3, 175-191. doi: 10.2147/CLEP.S12502

Lattif, A. A., Mukherjee, P. K., Chandra, J., Roth, M. R., Welti, R., Rouabhia, M., et al. (2011). Lipidomics of Candida albicans biofilms reveals phase-dependent production of phospholipid molecular classes and role for lipid rafts in biofilm formation. Microbiology 157, 3232-3242. doi: 10.1099/mic.0.051086-0

Lee, Y. S., Choi, K. M., Lee, S., Sin, D. M., Lim, Y., Lee, Y. M., et al. (2012). Myriocin, a serine palmitoyltransferase inhibitor, suppresses tumor growth in a murine melanoma model by inhibiting de novo sphingolipid synthesis. Cancer Biol. Ther. 13, 92-100. doi: 10.4161/cbt.13.2.18870

Lenardon, M. D., Munro, C. A., and Gow, N. A. (2010). Chitin synthesis and fungal pathogenesis. Curr. Opin. Microbiol. 13, 416-423. doi: 10.1016/j.mib.2010.05.002

Lyte, M. (2013). Microbial endocrinology in the microbiome-gut-brain axis: how bacterial production and utilization of neurochemicals influence behavior. PLoS Pathog. 9:e1003726. doi: 10.1371/journal.ppat.1003726

Lyte, M. (2014a). Microbial endocrinology and the microbiota-gut-brain axis. Adv. Exp. Med. Biol. 817, 3-24. doi: 10.1007/978-1-4939-0897-4_1

Lyte, M. (2014b). Microbial endocrinology: host-microbiota neuroendocrine interactions influencing brain and behavior. Gut Microbes 5, 381-389. doi: 10.4161/gmic. 28682

Macpherson, A., Zoheir, N., Awang, R. A., Culshaw, S., Ramage, G., Lappin, D. F., et al. (2014). The alpha 7 nicotinic receptor agonist PHA-543613 hydrochloride inhibits Porphyromonas gingivalis-induced expression of interleukin- 8 by oral keratinocytes. Inflamm. Res. 63, 557-568. doi: 10.1007/s00011-014-0725-5

Martin, S. W., and Konopka, J. B. (2004). Lipid raft polarization contributes to hyphal growth in Candida albicans. Eukaryot. Cell 3, 675e684. doi: 10.1128/EC.3.3.675-684.2004

Matera, C., and Tata. A. M. (2014). Pharmacological approaches to targeting muscarinic acetylcholine receptors. Recent Pat. CNS Drug Discov. 9, 85-100. doi: $10.2174 / 1574889809666141120131238$

Midkiff, J., Borochoff-Porte, N., White, D., and Johnson, D. I. (2011). Small molecule inhibitors of the Candida albicans budded-to-hyphal transition act through multiple signaling pathways. PLOS ONE 6:e25395. doi: 10.1371/journal.pone. 0025395

Miller, R. (2009). Mechanisms of action of antipsychotic drugs of different classes, refractoriness to therapeutic effects of classical neuroleptics, and individual variation in sensitivity to their actions: part II. Curr. Neuropharmacol. 7, 315-330. doi: 10.2174/157015909790031184

Momany, M. (2002). Polarity in filamentous fungi: establishment, maintenance and new axes. Curr Opin. Microbiol. 5, 580-585. doi: 10.1016/S1369-5274(02) 00368-5

Mor, V., Rella, A., Farnoud, A. M., Singh, A., Munshi, M., Bryan, A., et al. (2015). Identification of a new class of antifungals targeting the synthesis of fungal sphingolipids. mBio 6, e00647. doi: 10.1128/mBio.00647-15

Morace, G., and Borghi, E. (2010). Fungal infections in ICU patients: epidemiology and the role of diagnostics. Minerva Anestesiol. 76, 950-956.

Mormeneo, D., Manresa, A., Casas, J., Llebaria, A., and Delgado, A. (2008). Fungal growth inhibitory properties of new phytosphingolipid analogues. $J$. Appl. Microbiol. 104, 1075-1081. doi: 10.1111/j.1365-2672.2007.03635.x

Morrell, M., Fraser, V. J., and Kollef, M. H. (2005). Delaying the empiric treatment of Candida bloodstream infection until positive blood culture results are obtained: a potential risk factor for hospital mortality. Antimicrob. Agents Chemother. 49, 3640-3645. doi: 10.1128/AAC.49.9.3640-3645.2005

Mukherjee, P. K., Chandra, J., Kuhn, D. M., and Ghannoum, M. A. (2003). Mechanism of fluconazole resistance in Candida albicans biofilms: phasespecific role of efflux pumps and membrane sterols. Infect. Immun. 71, 4333-4340. doi: 10.1128/IAI.71.8.4333-4340.2003 
Nett, J. E., Crawford, K., Marchillo, K., and Andes, D. R. (2010a). Role of Fks1p and matrix glucan in Candida albicans biofilm resistance to an echinocandin, pyrimidine, and polyene. Antimicrob. Agents Chemother. 54, 3505-3508. doi: 10.1128/AAC.00227-10

Nett, J. E., Sanchez, H., Cain, M. T., and Andes, D. R. (2010b). Genetic basis of Candida biofilm resistance due to drug-sequestering matrix glucan. J. Infect. Dis. 202, 171-175. doi: 10.1086/651200

Nett, J. E., Lepak, A. J., Marchillo, K., and Andes, D. R. (2009). Time course global gene expression analysis of an in vivo Candida biofilm. J. Infect. Dis. 200, 307-313. doi: 10.1086/599838

Olianas, M. C., Maullu, C., and Onali, P. (1997). Effects of clozapine on rat striatal muscarinic receptors coupled to inhibition of adenylyl cyclase activity and on the human cloned $\mathrm{m} 4$ receptor. Br. J. Pharmacol. 122, 401-408. doi: 10.1038/sj.bjp.0701357

Olianas, M. C., Maullu, C., and Onali, P. (1999). Mixed agonist-antagonist properties of clozapine at different human cloned muscarinic receptor subtypes expressed in Chinese hamster ovary cells. Neuropsychopharmacology 20, 263-270. doi: 10.1016/S0893-133X(98)00048-7

Pierce, C. G., Srinivasan, A., Uppuluri, P., Ramasubramanian, A. K., and LópezRibot, J. L. (2013). Antifungal therapy with an emphasis on biofilms. Curr. Opin. Pharmacol. 13, 726-730. doi: 10.1016/j.coph.2013.08.008

Pohanka, M. (2012). Alpha7 nicotinic acetylcholine receptor is a target in pharmacology and toxicology. Int. J. Mol. Sci. 13, 2219-2238. doi: 10.3390/ijms13022219

Rajendran, R., Borghi, E., Falleni, M., Perdoni, F., Tosi, D., Lappin, D. F., et al. (2015). Acetylcholine protects against Candida albicans infection by inhibiting biofilm formation and promoting hemocyte function in a Galleria mellonella infection model. Eukaryot. Cell 14, 834-844. doi: 10.1128/EC.00067-15

Ramage, G., Bachmann, S., Patterson, T. F., Wickes, B. L., and Lopez-Ribot, J. L. (2002). Investigation of multidrug efflux pumps in relation to fluconazole resistance in Candida albicans biofilms. J. Antimicrob. Chemother. 49, 973-980. doi: 10.1093/jac/dkf049

Ramage, G., Martínez, J. P., and Lòpez-Ribot, J. L. (2006). Candida biofilms on implanted biomaterials: a clinically significant problem. FEMS Yeast Res. 6, 979-986. doi: 10.1111/j.1567-1364.2006.00117.x

Ramage, G., Robertson, S. N., and Williams, C. (2014). Strength in numbers: antifungal strategies against fungal biofilms. Int. J. Antimicrob. Agents. 43, 114-120. doi: 10.1016/j.ijantimicag.2013.10.023

Riquelme, M. (2013). Tip growth in filamentous fungi: a road trip to the apex. Annu. Rev. Microbiol. 67, 587-609. doi: 10.1146/annurev-micro-092412-155652

Romani, L. (2011). Immunity to fungal infections. Nat. Rev. Immunol. 11, 275-288. doi: $10.1038 /$ nri2939

Rosas-Ballina, M., Olofsson, P. S., Ochani, M., Valdes-Ferrer, S. I., Levine, Y. A., Reardon, C., et al. (2011). Acetylcholine-synthesizing T cells relay neural signals in a vagus nerve circuit. Science 334, 98-101. doi: 10.1126/science.1209985

Russo, P., Del Bufalo, A., Milic, M., Salinaro, G., Fini, M., and Cesario, A. (2014). Cholinergic receptors as target for cancer therapy in a systems medicine perspective. Curr. Mol. Med. 14, 1126-1138. doi: $10.2174 / 1566524014666141015152601$

Sabi, R., Vrey, P., and Van Rensburg, C. E. (2012). Carbohydrate-derived fulvic acid (CHD-FA) inhibits carrageenan-induced inflammation and enhances wound healing: efficacy and toxicity study in rats. Drug Dev. Res. 73, 18-23. doi: $10.1002 / \mathrm{ddr} .20445$

Sales, M. E. (2013). Cholinergic drugs as therapeutic tools in inflammatory diseases: participation of neuronal and non-neuronal cholinergic systems. Antiinflamm. Antiallergy Agents Med. Chem. 12, 109-116. doi: 10.2174/1871523011312020002

Sandrini, S., AlDriwesh, M., Alruways, M., and Freestone, P. (2015). Microbial endocrinology: host-bacteria communication within the gut microbiome. J. Endocrinol. 225, R21-R34. doi: 10.1530/joe-14-0615
Sharma, S., Alfatah, M., Bari, V. K., Rawal, Y., Paul, S., and Ganesan, K. (2014). Sphingolipid biosynthetic pathway genes FEN1 and SUR4 modulate amphotericin B resistance. Antimicrob. Agents Chemother. 58, 2409-2414. doi: 10.1128/AAC.02130-13

Sherry, L., Jose, A., Murray, C., Williams, C., Jones, B., Millington, O., et al. (2012). Carbohydrate derived fulvic acid: an in vitro investigation of a novel membrane active antiseptic agent against Candida albicans biofilms. Front. Microbiol. 3:116. doi: 10.3389/fmicb.2012.00116

Sherry, L., Millhouse, E., Lappin, D. F., Murray, C., Culshaw, S., Nile, C. J., et al. (2013). Investigating the biological properties of carbohydrate derived fulvic acid (CHD-FA) as a potential novel therapy for the management of oral biofilm infections. BMC Oral Health 13:47. doi: 10.1186/14726831-13-47

Singh, A., and Del Poeta, M. (2011). Lipid signalling in pathogenic fungi. Cell. Microbiol. 13, 177-185. doi: 10.1111/j.1462-5822.2010.01550.x

Snyman, J. R., Dekker, J., Malfeld, S. C. K., and Van Rensburg, C. E. (2002). Pilot study to evaluate the safety and therapeutic efficacy of topical oxifulvic acid in atopic volunteer. Drug Dev. Res. 57, 40-43. doi: 10.1002/ddr.10116

Strettoi, E., Gargini, C., Novelli, E., Sala, G., Piano, I., Gasco, P., et al. (2010). Inhibition of ceramide biosynthesis preserves photoreceptor structure and function in a mouse model of retinitis pigmentosa. Proc. Natl. Acad. Sci. U.S.A. 107, 18706-18711. doi: 10.1073/pnas.1007644107

Taff, H. T., Mitchell, K. F., Edward, J. A., and Andes, D. R. (2013). Mechanisms of Candida biofilm drug resistance. Future Microbiol. 8, 1325-1337. doi: $10.2217 / \mathrm{fmb} .13 .101$

Tracey, K. J. (2010). Understanding immunity requires more than immunology. Nat. Immunol. 11, 561-564. doi: 10.1038/ni0710-561

van Rensburg, C. E. J., Van Straten, A., and Dekker, J. (2000). An in vitro investigation of the antimicrobial activity of oxifulvic acid. J. Antimicrob. Chemother. 46, 853. doi: 10.1093/jac/46.5.853

Verbout, N. G., and Jacoby, D. B. (2012). Muscarinic receptor agonists and antagonists: effects on inflammation and immunity. Handb. Exp. Pharmacol. 208, 403-427. doi: 10.1007/978-3-642-23274-9_17

Wessler, I., and Kirkpatrick, C. J. (2008). Acetylcholine beyond neurons: the nonneuronal cholinergic system in humans. Br. J. Pharmacol. 154, 1558-1571. doi: 10.1038/bjp.2008.185

Wiebelhaus, J. M., Vunck, S. A., Meltzer, H. Y., and Porter, J. H. (2012). Discriminative stimulus properties of $\mathrm{N}$-desmethylclozapine, the major active metabolite of the atypical antipsychotic clozapine, in C57BL/6 mice. Behav. Pharmacol. 23, 262-270. doi: 10.1097/FBP.0b013e328 3534332

Zoheir, N., Lappin, D. F., and Nile, C. J. (2012). Acetylcholine and the alpha 7 nicotinic receptor: a potential therapeutic target for the treatment of periodontal disease? Inflamm. Res. 61, 915-926. doi: 10.1007/s00011-012 0513-Z

Zorn, S. H., Jones, S. B., Ward, K. M., and Liston, D. R. (1994). Clozapine is a potent and selective muscarinic M4 receptor agonist. Eur. J. Pharmacol. 269, R1-R2. doi: 10.1016/0922-4106(94)90047-7

Conflict of Interest Statement: The authors declare that the research was conducted in the absence of any commercial or financial relationships that could be construed as a potential conflict of interest.

Copyright (c) 2015 Borghi, Morace, Borgo, Rajendran, Sherry, Nile and Ramage. This is an open-access article distributed under the terms of the Creative Commons Attribution License (CC BY). The use, distribution or reproduction in other forums is permitted, provided the original author(s) or licensor are credited and that the original publication in this journal is cited, in accordance with accepted academic practice. No use, distribution or reproduction is permitted which does not comply with these terms. 